\title{
Nilai-Nilai Pancasila dalam Perspektif Sosial- Budaya
}

\section{Prof. Dr. Andrik Purwasito, DEA}

Program Studi S3 Kajian Budaya, Universitas Sebelas Maret
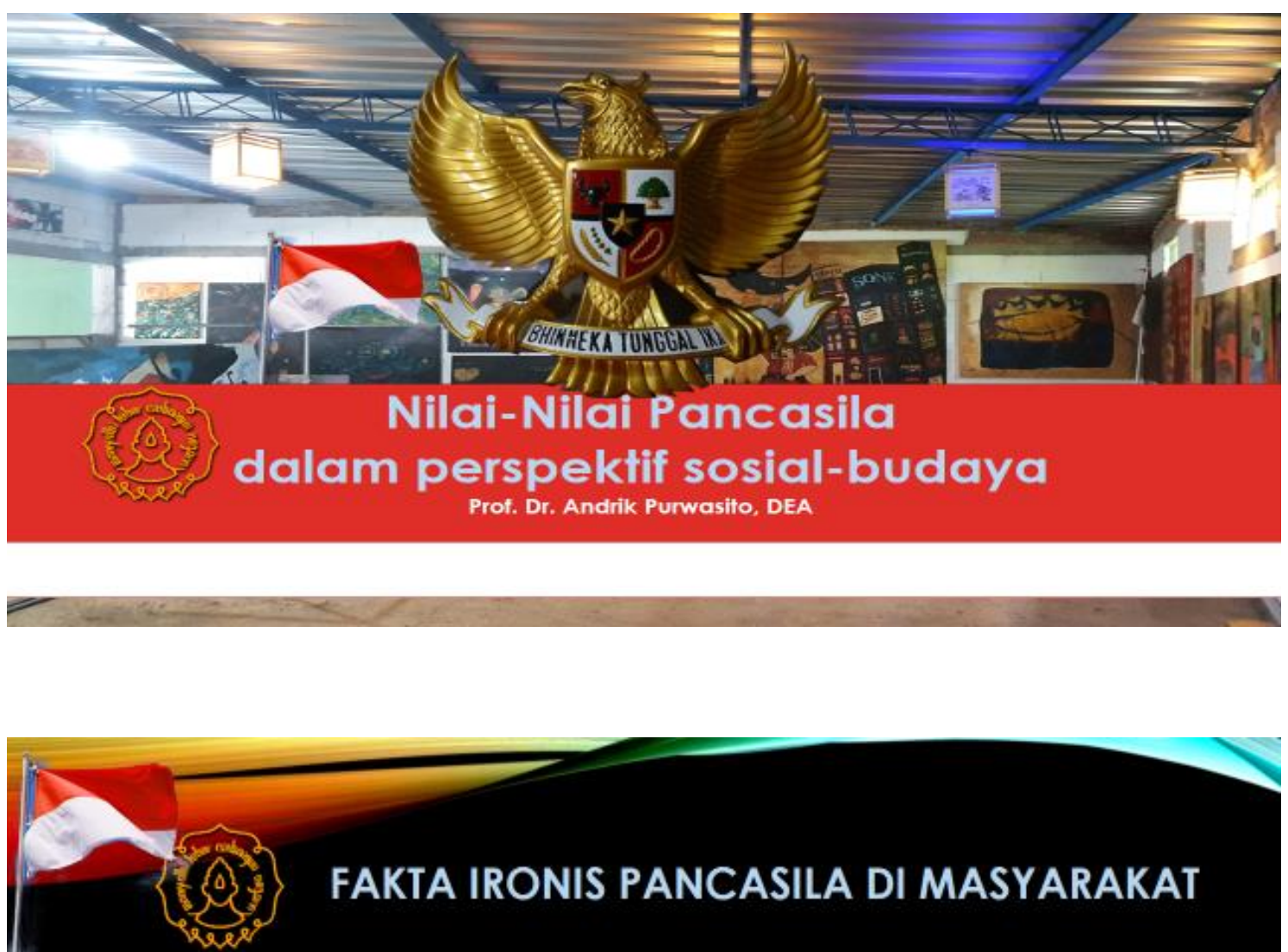

- Hasil Survey LIPI, 25\% siswa dan mahasiswa yang menganggap Pancasila tidak lagi relevan. (Hasil penelitian Lembaga llmu Pengetahuan Indonesia (LIPI) pada 2016)

- Hasil survei menemukan, ada $9 \%$ (sekitar 15 juta jiwa) rakyat kita menginginkan khilafah (Saiful Mujani Research and Consulling (SMRC) pada 2017).

- Hasil survey BPS, (1) lunturnya wawasan kebangsaan.

- Hasil (2) : hanya $67-78 \%$ yang tahu tentang empat pilar negara : Pancasila, NKRI, UUD 1945, dan Bhinneka Tunggal lka.

- Hasil (3) : 10\% masyarakat tidak mampu menyebutkan butir-butir Pancasila. (Survei yang dilakukan di 181 kabupaten/kota, di 33 provinsi dan melibatkan 12.056 responden) 

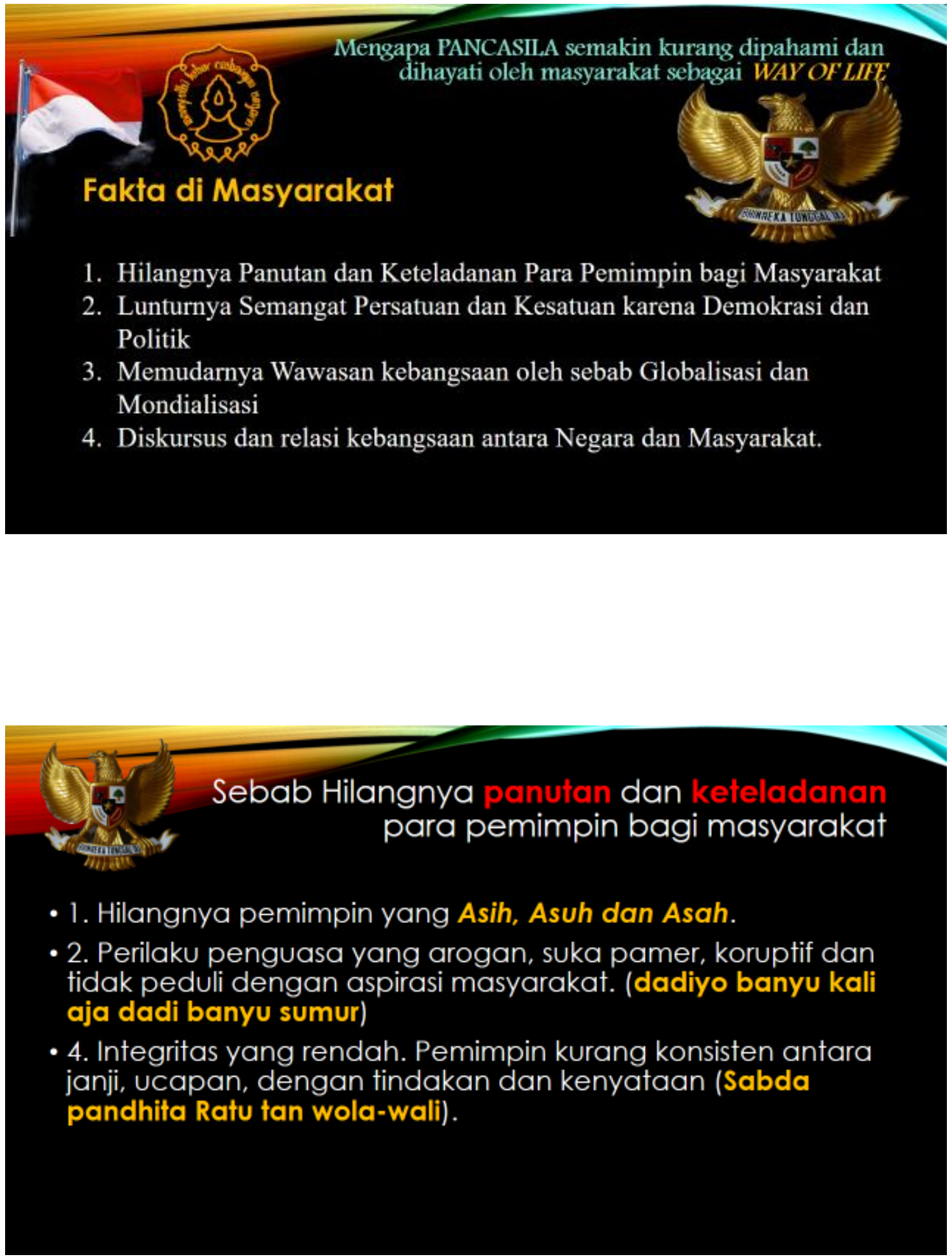

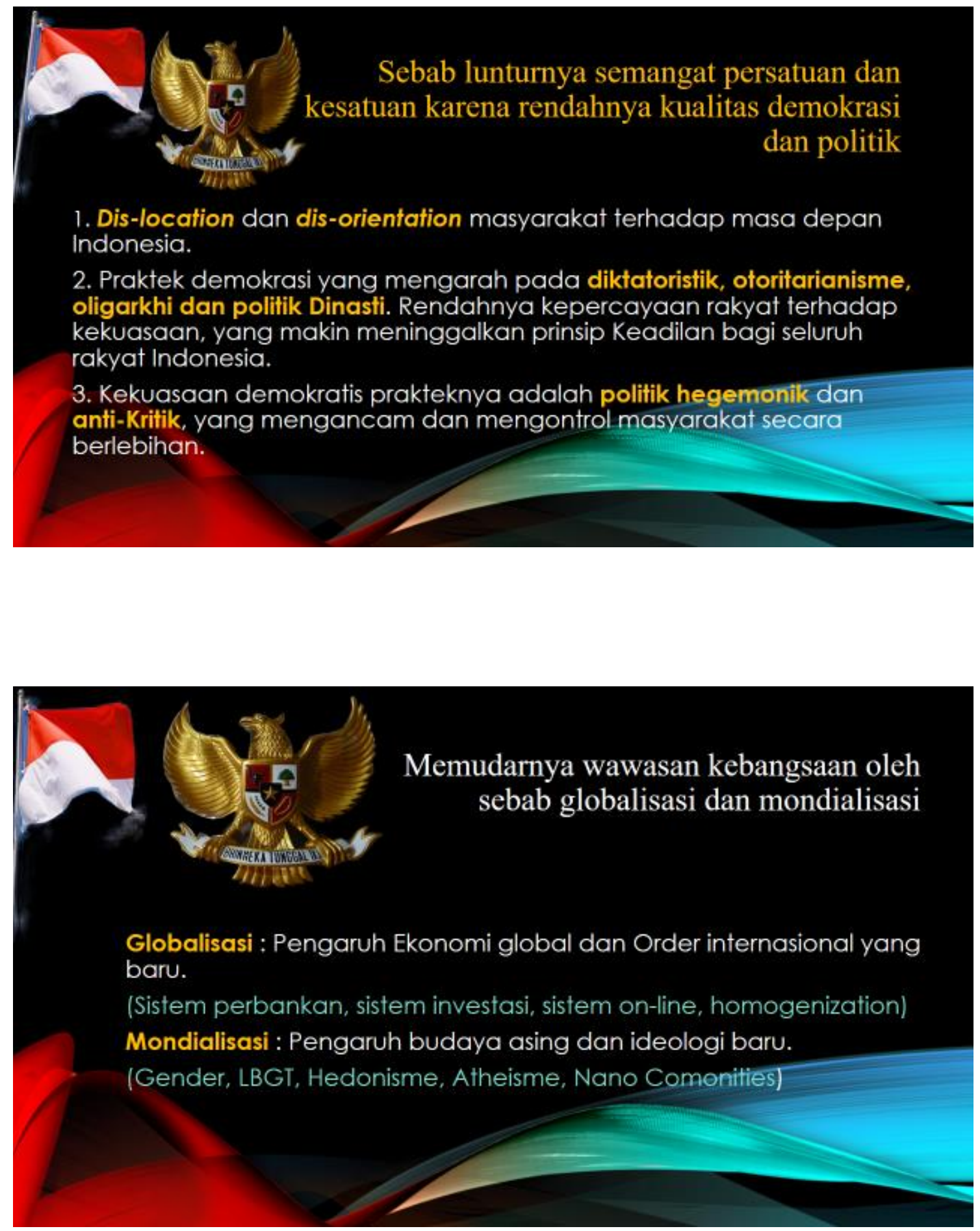

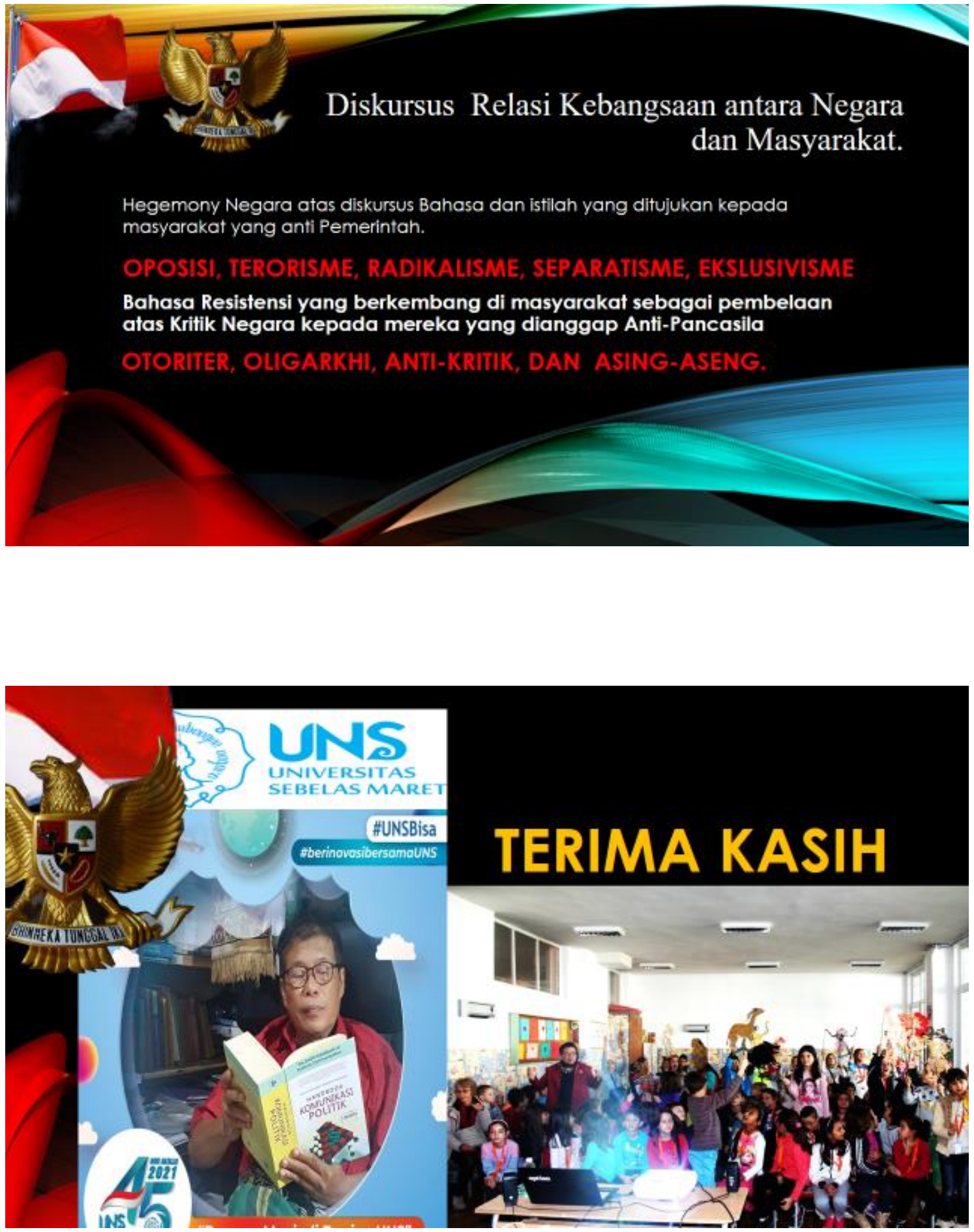